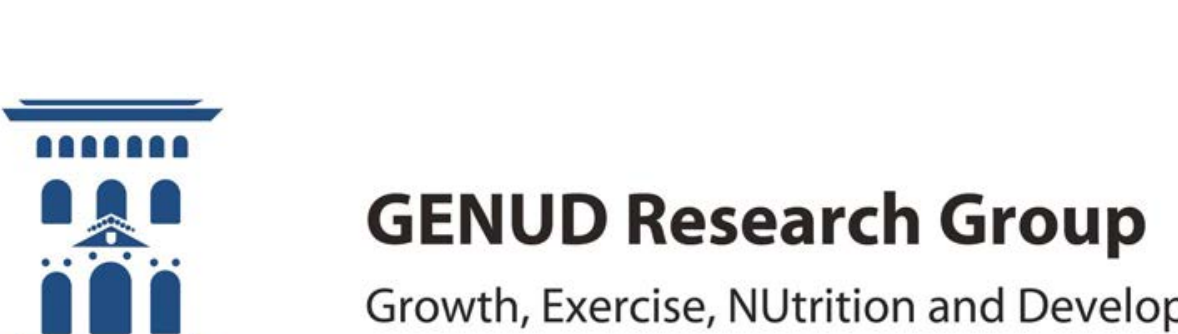

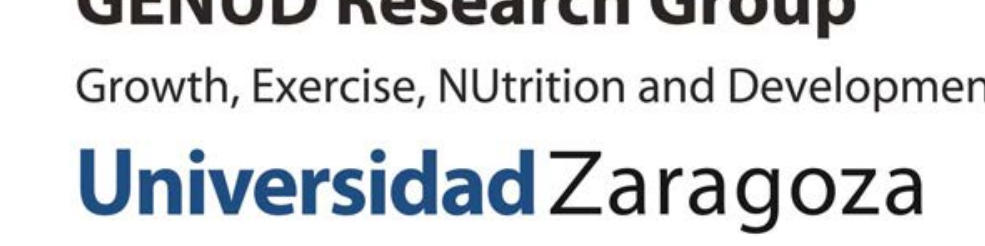

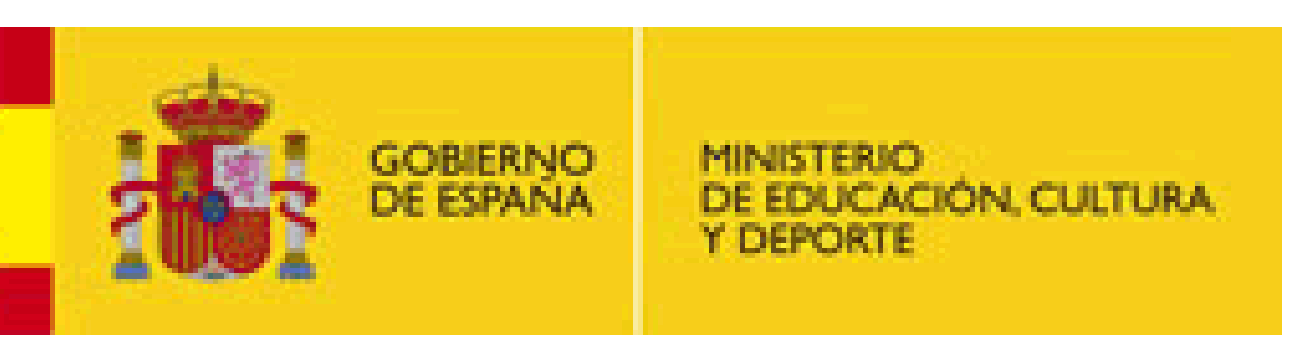

\section{Effects of Plaving Surfaces on Volumetric Bone Mineral Density in Adolescent Male Soccer Plavers}

José A. Casajus ${ }^{1,2^{*}}$ Ángel Matute-Llorente ${ }^{1,2}$, Gabriel Lozano-Berges ${ }^{1,2}$, Jorge Marín-Puyalto ${ }^{1,2}$

Alejandro Gómez-Bruton ${ }^{1,2}$, Alejandro González-Agüero ${ }^{1,2}$, Germán Vicente-Rodríguez

\title{
Introduction
}

It has been well recognized that impact loading in sporting activity is highly associated with bone accretion. Recently, Carmona et al. ${ }^{1}$ showed that bone mass accretion was similar bone in prepubescent soccer players independently of the playing surface (artificial turf vs. non-grass ground surface). However, the osteogenic effects on volumetric bone mineral density (vBMD) generated by four different playing surfaces of the same sport are unknown.

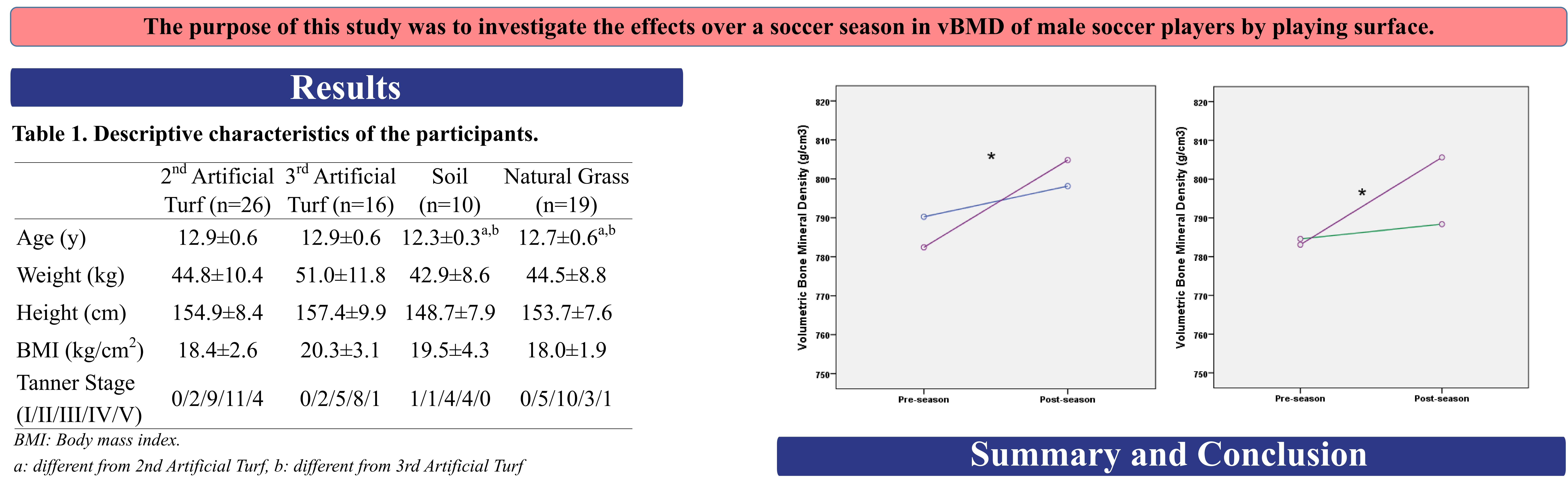

a: different from 2nd Artificial Turf b: different from 3rd Artificial Turf

A group by time interaction was found for $\mathrm{VBMD}$ at $38 \%$ of the distal tibia $(p=0.029$ and $f=0.38)$.

Figure 1. Groups and playing surfaces.

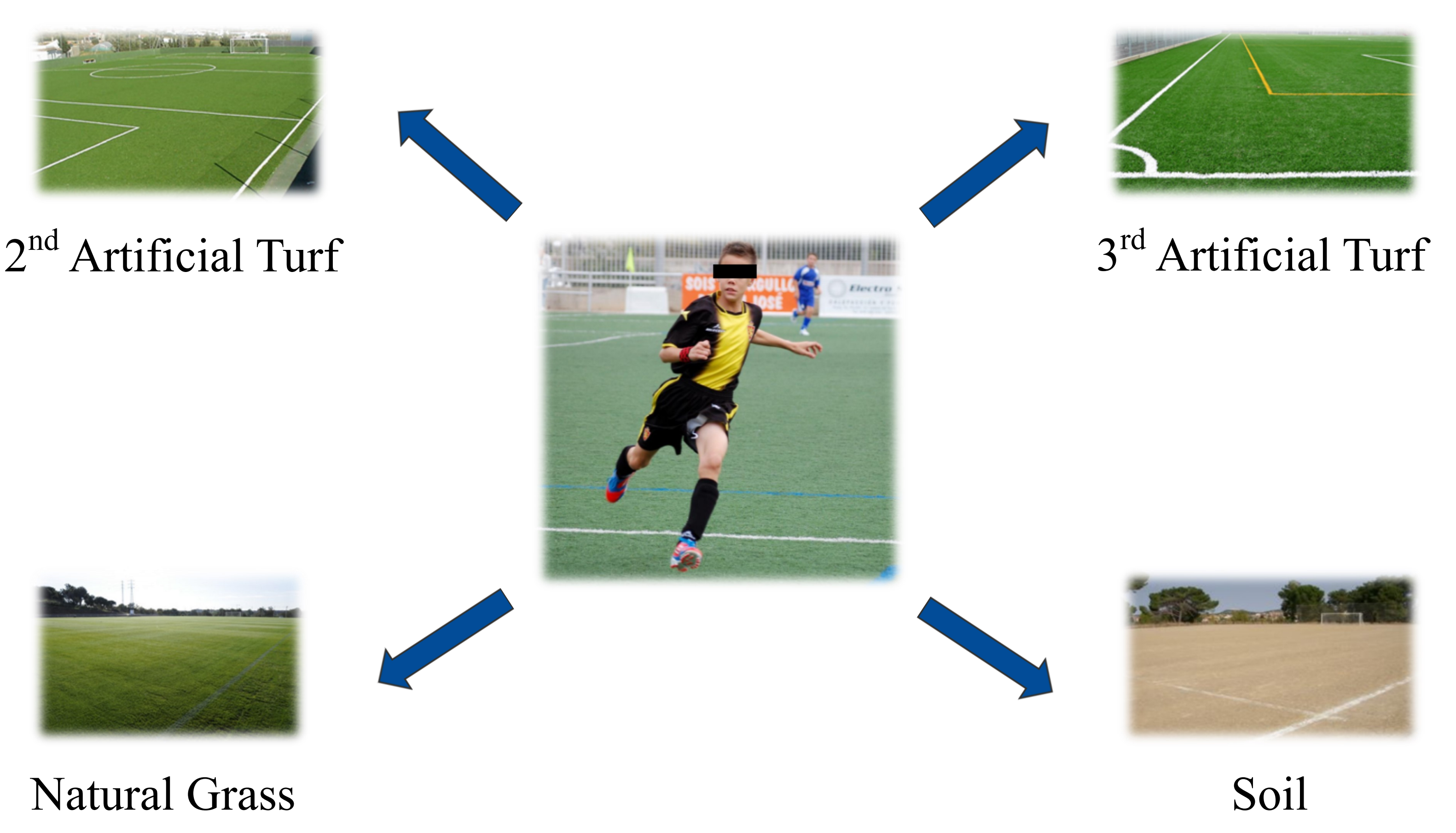

Figure 2. Peripheral computed tomography (38\% of the tibia).

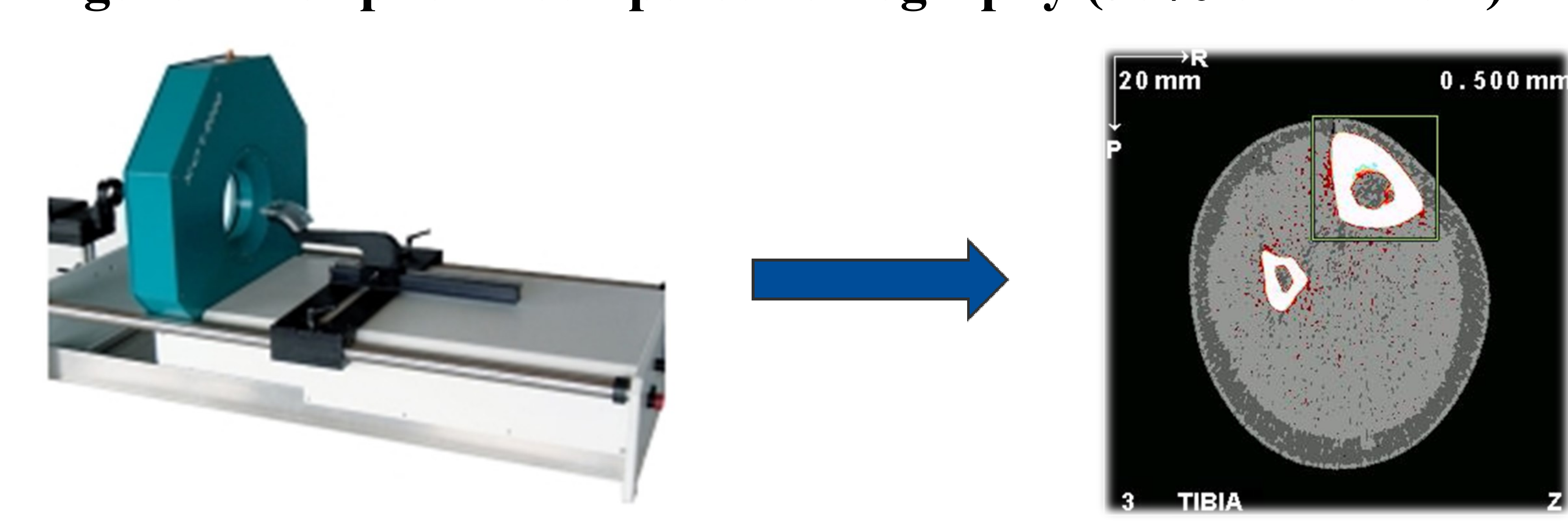

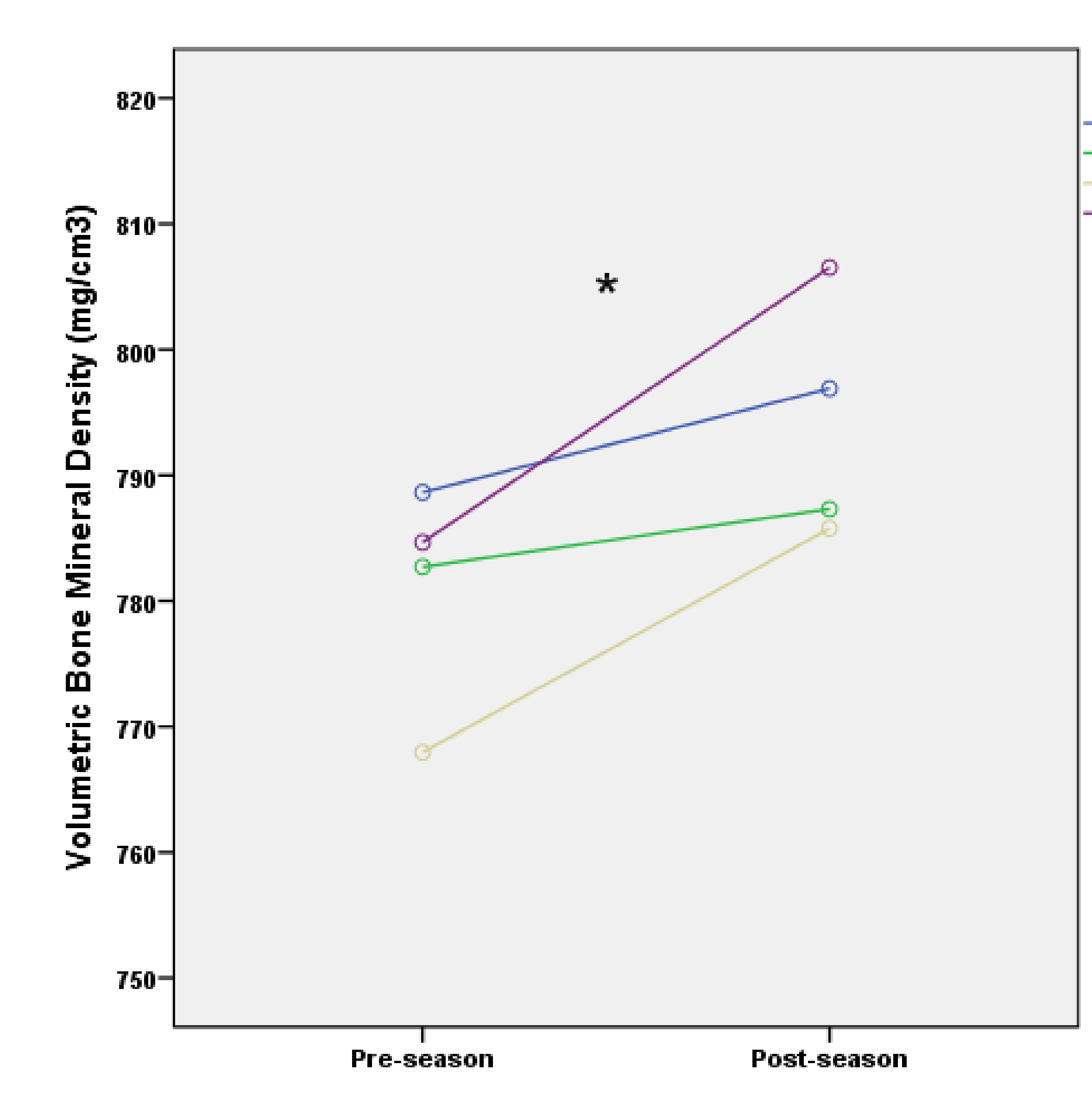

When pairwise comparisons were carried out, NG showed group by time interactions compared to $2^{\text {nd }}$ generation artificial turf ( 782 to $804 \mathrm{mg} / \mathrm{cm}^{3}$ vs. 790 to $798 \mathrm{mg} / \mathrm{cm}^{3} ; p=0.007$ and $\left.f=0.50\right)$, and to $3^{\text {rd }}$ generation artificial turf (782 to $804 \mathrm{mg} / \mathrm{cm}^{3}$ vs. 784 to $788 \mathrm{mg} / \mathrm{cm}^{3}$; $p=0.027$ and $f=0.35$ )

Soccer players training and playing in NG pitch showed better values in vBMD acquisition than those on $2^{\text {nd }}$ and $3^{\text {rd }}$ generation artificial turf. Despite previous studies presented no differences on bone mass accretion independently of the playing surface. Our results suggest that NG is the most recommended playing surface to improve vBMD in the non-dominant tirecom bia.

\section{References}

1. Carmona MP et al. (2014) Int J Sports Med 35(1):55-61 Acknowledgments

\section{Download the poster here}

Supported by Spanish Ministerio de Economía Competitividad (Project DEP 2012-32724) and FPU Grant (AP12-2854).
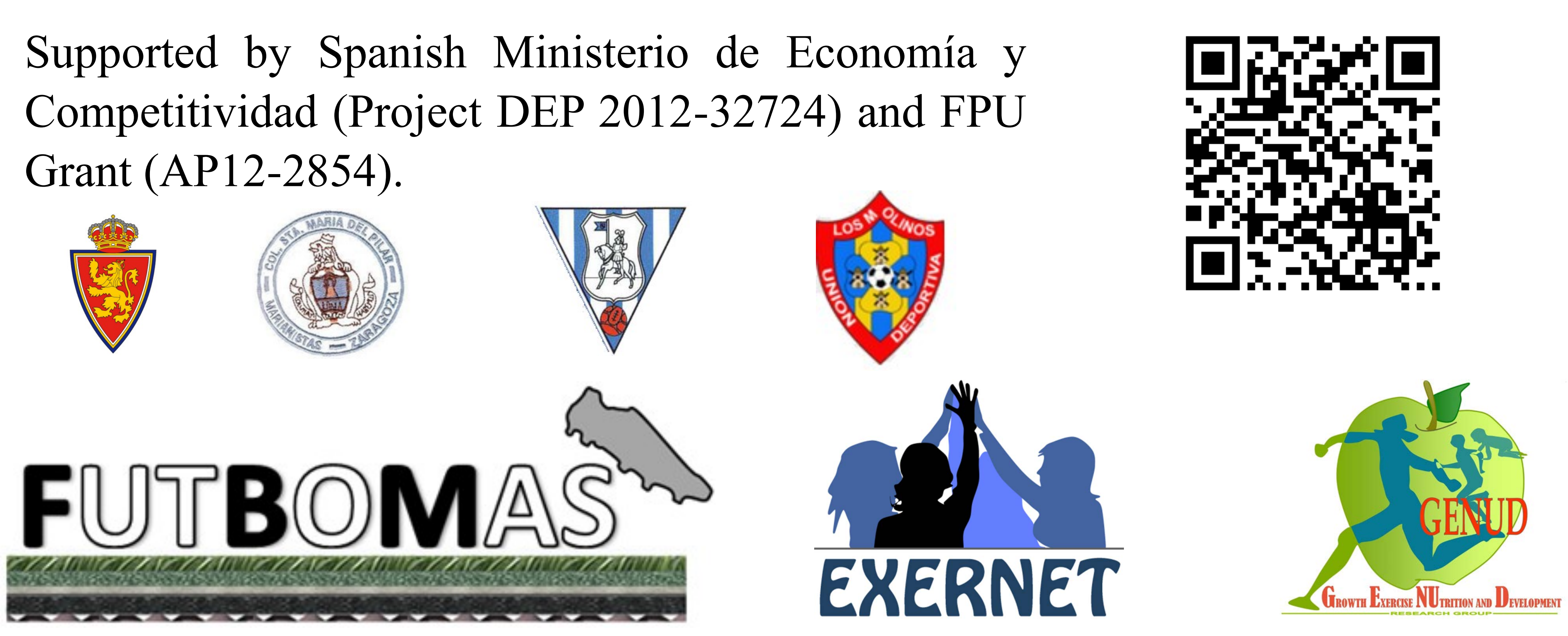